\title{
CARNE É FRIBOI? ANÁLISE DISCURSIVA DE UMA CAMPANHA PUBLICITÁRIA NO FACEBOOK
}

\author{
Ane Cristina Thurow ${ }^{i}$ \\ Ercília Ana Cazarinii \\ Jeferson da Silva Schneider ${ }^{\text {iii }}$
}

\begin{abstract}
Resumo: As campanhas publicitárias movimentam saberes que são reproduzidos pelo sujeito ao utilizar a linguagem. Este sujeito, atravessado pela ideologia, indica sua posição frente ao dizer, deixando rastros das possíveis relações de forças que se estabelecem a partir da publicidade. Neste estudo, buscamos analisar discursivamente, à luz da Análise de Discurso de filiação pecheuxtiana, os efeitos de sentido produzidos a partir da imagem e de dois enunciados presentes na publicidade da empresa Friboi: "O açougue tem Friboi?" e "Então você pode confiar". Para a análise, consideramos algumas noções primordiais para a interpretação como: discurso, sujeito, formação discursiva e condições de produção. Com este trabalho, esperamos evidenciar, por meio das condições de produção, os prováveis efeitos de sentido produzidos em diferentes formações discursivas configuradas.
\end{abstract}

Palavras-Chave: Discurso. Campanha publicitária. Formação Discursiva. Condições de produção.

\begin{abstract}
The advertising campaigns move distinct knowledges that are reproduced by the subject when using language. This subject, traversed by ideology, indicates his position in saying, leaving traces of the possible force relations that are established from the advertisement. In this study, we sought to discursively analyze, based on the Discourse Analysis of Pecheuxtian orientation, the effects of meaning produced both from the image and from two statements present in the Friboi's company advertisement: "The butcher has Friboi" and "So you can trust". In order to conduct the analysis, we consider some fundamental notions to the interpretation, such as discourse, subject, discursive formation and conditions of production. With this work, we hope to show, through the conditions of production, the probable effects of meaning produced in different configured discursive formations.
\end{abstract}

Keywords: Discourse. Advertising campaign. Discursive Formation. Conditions of production.

\footnotetext{
i Doutoranda e mestre em Letras pela Universidade Católica de Pelotas (PPGL/UCPel). E-mail: ane.thurow@gmail.com.

ii Doutora em Letras pela Universidade Federal do Rio Grande do Sul (UFRGS). Docente do Programa de Pós-Graduação em Letras da Universidade Católica de Pelotas (PPGL/UCPel). E-mail: eacazarin@gmail.com.

iii Mestre em Letras pela Universidade Católica de Pelotas (PPGL/UCPel). Docente da Universidade Católica de Pelotas (UCPel). E-mail: jeferson.brasileiro@gmail.com.
} 
EID\&A - Revista Eletrônica de Estudos Integrados em Discurso e Argumentação, Ilhéus, n. 14, jul/dez.2017.

\section{Introdução}

Em meio a tantas campanhas publicitárias as quais somos expostos diariamente, emergem muitos sentidos pelo dinamismo desse tipo de discurso. O entendimento dos critérios imperativos comerciais acaba se consolidando no imaginário social e, por sua vez, proporciona efeitos de sentido que extrapolam os aspectos comerciais, fator que não causa estranhamento para quem preconiza as ideias da Análise de Discurso (AD).

Ao tentarmos focar algumas destas questões, refletimos sobre os efeitos de sentido produzidos pelo sujeito e as pistas das possíveis relações de forças que se constituem na campanha publicitária. Nossa apreciação parte de uma postagem no Facebook, mais especificamente na comunidade/ fanpage da empresa frigorífica Friboi, que nos permite demonstrar relações sóciohistóricas no seu texto verbal e não verbal.

No presente estudo, ocupamo-nos em analisar discursivamente os efeitos de sentidos produzidos a partir da imagem e de dois enunciados presentes na publicidade da empresa Friboi: "O açougue tem Friboi?" e "Então você pode confiar". Nossa descrição e compreensão partem das condições de produção e dos prováveis efeitos de sentido produzidos no interior de uma formação discursiva. Pretendemos evocar as implicações políticas e sociais que circundam o efeito de discurso publicitário em questão e suas possíveis (re)significações por meio de entrecruzamentos e/ou deslizes.

\section{Noções teóricas}

A disciplina interpretativa da AD, formulada por Michel Pêcheux, permite ao analista entender o discurso para além do contexto situacional, possibilitando uma interpretação que considera a historicidade e as condições de produção de determinado dizer. Consideramos que "as palavras, expressões, proposições, etc., mudam de sentido segundo as posições sustentadas por aqueles que as empregam", porque os sentidos dependem das filiações ideológicas dos sujeitos do dizer (PÊCHEUX, 2009, p. 146).

Entendemos que o discurso é palavra em movimento, relacionado à produção de discursos anteriores e posteriores, e permite que os sentidos estejam em constante transformação. Esses sentidos produzidos pelo discurso estão ligados à historicidade, sendo que, "todo discurso é visto como um estado de um processo discursivo mais amplo, contínuo. Não há desse 
EID\&A - Revista Eletrônica de Estudos Integrados em Discurso e Argumentação, Ilhéus, n. 14, jul/dez.2017.

modo, começo absoluto nem ponto final para o discurso. Um dizer tem relação com outros dizeres realizados, imaginados ou possíveis" (ORLANDI, 2012a, p. 39).

O discurso produz sentidos atrelados ao contexto sócio-histórico e tem relações com os já-ditos ativados pelo sujeito a partir de sua imaginária inscrição em uma formação discursiva (FD). O sujeito, interpelado pela ideologia e pela história, produz seu dizer imaginando um sentido. No entanto, esse sujeito não tem como determinar o sentido, pois o sentido é produzido na relação entre os interlocutores. Tanto o sujeito quanto o sentido se constituem na e pela linguagem (ORLANDI, 2012a).

A linguagem, como noção da $A D$, tem condição de incompletude, o que permite sua relação com o simbólico e com o real do discurso. Segundo Orlandi (2012a, p. 51), "na transparência da linguagem, é a ideologia que fornece as evidências que apagam o caráter material do sentido e do sujeito", revelando sua opacidade e seus limites heterogêneos. Pela linguagem, percebemos os processos de significação, que podem ser expostos pela deriva, pela significação produzida no momento do dizer.

Ao pensar sobre linguagem focamos na alimentação humana através da ingestão de carne, um ato que perpassa toda a história das civilizações. A alimentação em si, não apenas através da ingestão de carne, é vista como uma ação que possui caráter simbólico que, segundo DaMatta (2004), estabelece uma identidade, define um grupo, classe e pessoa. Segundo o autor, podemos ainda dizer que, “... o mundo das comidas não nos leva para o mercado ou para o governo, mas para casa, para os parentes e amigos: para nossos companheiros de teto e de mesa" (DAMATTA, 2004, p. 30).

Ao mesmo tempo em que a alimentação possui caráter de união e consolidação de uma classe, o consumo de carne é, em parte, uma segregação de caráter social devido ao custo monetário passado ao consumidor que, por sua vez, resulta no caráter simbólico de status social. Essa concepção de caráter simbólico, referente ao status, está presente em nossa cultura há séculos. Ao lembrarmo-nos da colonização de nosso país, temos um exemplo desse caráter histórico, pois, os escravos, que eram a mão de obra para os grandes criadores de gado, não tinham como base de sua alimentação a carne, mas, sim, vegetais. O caráter simbólico surge no discurso através das relações interpessoais e das instituições alimentícias. 
EID\&A - Revista Eletrônica de Estudos Integrados em Discurso e Argumentação, Ilhéus, n. 14, jul/dez.2017.

Ao entrarmos no campo da AD, temos o discurso e sua dependência com a interpretação do leitor, o que repercute na condição dos sentidos serem produzidos em detrimento daqueles que não são produzidos e que, por sua vez, relacionam-se diretamente às condições de leitura de um determinado enunciado/texto. $O$ ato da leitura envolve a interpretação do leitor em relação ao texto.

Ler constitui-se, assim, em uma prática social que mobiliza o interdiscurso, conduzindo o leitor, enquanto sujeito histórico, a inscrever-se em uma disputa de interpretações. Este desestabiliza sentidos já dados, daí o efeito de inconsistência de todo e qualquer texto, que se caracteriza como uma heterogeneidade provisoriamente estruturada. (CAZARIN, 2006, p. 302)

Essa heterogeneidade do texto ocorre tendo em vista que outros textos nele se fazem presentes. Ela é provisória dada a incompletude de todo e qualquer discurso. As relações entre textos, por sua vez, remetem-nos aos lugares sociais, às posições-sujeito a partir das quais se diz e/ou se lê. Para Pêcheux (2008, p. 45), as diferentes leituras consistem "em multiplicar as relações entre o que é dito aqui (em tal lugar), e dito assim e não de outro jeito, com o que é dito em outro lugar e de outro modo, a fim de se colocar em posição de 'entender' a presença de não-ditos no interior do que é dito”.

Para o autor, a leitura amplia as relações, de modo que filiar-se a um dizer, a uma posição, implica estar identificado com um conjunto de saberes e não com outros, segundo os domínios de diferentes formações discursivas, as quais definem o que pode/deve/convém ou não ser dito a partir de um determinado lugar. Para tanto, uma FD se caracteriza pela constituição de sentidos permeados pelas formações ideológicas.

As formações discursivas, por sua vez, representam, no discurso, as formações ideológicas. Desse modo, os sentidos sempre são determinados ideologicamente. Não há sentido que não o seja. Tudo que dizemos tem, pois, um traço ideológico em relação a outros traços ideológicos. $\mathrm{E}$ isto não está na essência das palavras, mas na discursividade, isto é, na maneira como, no discurso, a ideologia produz seus efeitos, materializando-se nele. (ORLANDI, 2012a, p. 43)

Salientamos que a FD não é homogênea, mas, sim, um espaço de natureza heterogênea. Ela reflete a ideologia que se relaciona com a linguagem e é sempre constituída por formações ideológicas diversificadas. Para Pêcheux (2009, p. 147), uma FD é "aquilo que, numa formação ideológica dada, isto é, a partir de uma posição dada numa conjuntura dada, determinada pelo estado da luta de classes, determina o que pode e deve ser dito". 
EID\&A - Revista Eletrônica de Estudos Integrados em Discurso e Argumentação, Ilhéus, n. 14, jul/dez.2017.

Nessa perspectiva, a ideologia interpela o sujeito, de maneira que o leva a tomar "uma posição de sujeito como uma relação determinada que se estabelece em uma formulação entre um sujeito enunciador e o sujeito de saber de uma determinada FD" (COURTINE, 2009, p. 88). Através de um posicionamento, o sujeito ao dizer, inscreve-se em uma FD.

Com isso, trazer para a análise a materialidade discursiva, é fazer as ligações possíveis entre os "nós" que constituem uma sequência discursiva, respeitando condições e relações pré-estabelecidas. Atribuir sentidos a um enunciado, ligar a ele suas redes de significados, parte de princípios relevantes às perspectivas do enunciado, que, por sua vez, nos permite compreender a relação de homogeneidade e heterogeneidade em uma sequência discursiva, como diz Courtine (2009).

A inscrição de um enunciado num conjunto de formulações - como 'um nó em uma rede' - deverá ser caracterizada a partir de uma pluralidade de pontos, constituindo, ao redor de sequências discursivas tomadas como ponto de referência, uma rede de formulações extraídas de sequências discursivas, cujas condições de produção serão, ao mesmo tempo, homogêneas e heterogêneas em relação à sequência discursiva de referência. (COURTINE, 2009, p. 90)

Dessa forma, tramar estes pontos para efetivar uma análise é conseguirmos convergir os enunciados a filiações comuns, neste caso, para uma mesma FD. É importante ainda, refletirmos que, no interior de uma mesma FD, posições distintas convivem ora com embates, ora com aproximações.

No caso de enunciados publicitários, podemos dizer, de modo geral, que pertencem a um discurso que perpassa por diferentes FDs e, segundo seu engajamento a uma ordem do dizer, fazem menção à política, economia, status social, consumismo entre outras. No caso do enunciado "O açougue tem FRIBOI?" (E1) e "Então você pode confiar" (E2), é possível traçar alguns paralelos que nos levam ao domínio de enunciados próprios daqueles que compreendem essa publicidade como tendenciosa a fim de conceituar o que é confiável e daqueles que condenam o consumo de carne a partir de sua marca. Temos uma FD mercantilista, representativa da empresa Friboi e favorável ao consumo de carne. Contudo, em seu interior, existem as divergências quanto aos saberes que circulam e são ditos ou não-ditos.

No texto em análise, a discursividade está presente tanto no verbal quanto no não verbal - ambos imbricam-se para produzir sentidos. Importa- 
EID\&A - Revista Eletrônica de Estudos Integrados em Discurso e Argumentação, Ilhéus, n. 14, jul/dez.2017.

nos, portanto, reconhecer a imagem como portadora de discurso. Segundo Ernst-Pereira e Quevedo (2013)

[...] o gesto de olhar - e mesmo o anterior, o de ver - é fundamentalmente um trabalho de leitura e, como tal, é realizado sempre por um sujeito histórico, atualizado no sujeito empírico/indivíduo, a partir de uma dada posição de interpretação e sob dadas condições de produção. (ERNST-PEREIRA; QUEVEDO, 2013, p. 268)

O gesto interpretativo do sujeito, em relação à imagem, movimenta saberes e sentidos que mobilizam o interdiscurso, determinado pela ideologia. Ao ler o texto não verbal, as filiações do sujeito interferem em sua interpretação, pois "gerada e gerida discursivamente, devemos admitir que o que a imagem 'mostra', o seu 'visível', não the é intrínseco, mas sim (sobre)determinado pela formação discursiva a partir da qual o sujeito histórico a produz" (ERNST-PEREIRA; QUEVEDO, 2013, p. 270).

No proceder desta análise, refletimos como a imagem e os enunciados E1 e E2 se inscrevem no interior da FD que comporta os saberes relacionados aos dizeres de uma publicidade, direcionada ao consumo de carne baseado em uma marca e como, dessa relação, amarram-se e se envolvem em outras discursividades. Também, apegamo-nos aos dizeres que direcionam a novos efeitos de sentido correlacionados aos saberes sócio-históricos.

\section{Facebook: espaço de inscrição da publicidade}

No caso em questão, partimos para a análise de uma publicidade que ganhou espaço a partir de sua vinculação na televisão através de um vídeo e sua divulgação imagética no Facebook. Pensar acerca desta propaganda é evocar as relações possíveis de análise, mas, para isso, partimos de uma leitura com foco na perspectiva discursiva, a qual implica levar em conta, que os sentidos são produzidos por sujeitos historicamente determinados e atravessados pelo inconsciente.

Neste caso, importa prestar atenção à organização social contemporânea que é marcada por relações de mercado que perpassa os estabelecimentos comerciais, sendo focado o produto e suas predicações a partir da publicidade. Os estabelecimentos em si são as pontes que dão o resultado monetário que implica deflagrar se o público alvo está aderindo ao produto através do ato de comprar. 
EID\&A - Revista Eletrônica de Estudos Integrados em Discurso e Argumentação, Ilhéus, n. 14, jul/dez.2017.

As relações de força/ mercado estão presentes na sociedade e se apresentam no meio midiático. Na mídia interativa, a informação é rápida e se propaga, influenciando "as pessoas no modo de agir, pensar e vestir, criando demandas e orientando estilos e discussões sociais" (THUROW; DOROW, 2015, p. 237). Nesse sistema, o texto (verbal ou não verbal) produz distintos efeitos de sentidos, sendo que o "sujeito, que é leitor, telespectador, navegador, internauta, interage de diferentes formas e é interpelado pela ideologia e pelo inconsciente, refletindo sua posição-sujeito" (THUROW; DOROW, 2015, p. 237).

Entendemos que o sujeito, em sua tomada de posição, cria laços sociais nas redes sociais, especialmente ao se vincular a uma comunidade/ fanpage, pois seus dizeres se inscrevem numa certa FD. Esse entendimento surge da menção de Recuero (2012, p. 604) de que "em ferramentas como o Facebook, onde as conexões são necessariamente recíprocas, é mais fácil percebê-las como laços sociais". Estes laços podem interferir na produção de dizeres e sentidos dentro e fora do espaço virtual, visto que o sujeito segue a fanpage e, possivelmente, inscreve-se na FD mercantilista, representativa da empresa Friboi.

Nosso foco não é o espaço virtual do Facebook como um todo, mas, sim, a comunidade/ fanpage da empresa Friboi, lugar que o sujeito pode "curtir", "comentar" e compartilhar" as publicações. A fanpage foi criada em 2012 e contava, em outubro de 2017, com mais de um milhão de curtidas e seguidores, o que entendemos como uma boa manutenção dos laços sociais. A postagem do dia 13 de agosto de 2013, nosso objeto de análise, obteve 83 comentários, 574 curtidas e 145 compartilhamentos.

Nesse trajeto, temos o discurso inscrito em um espaço definido, uma comunidade/ fanpage do Facebook, que deixa aparecer o caráter público do discurso. Discurso este que "busca" no interdiscurso, alguns enunciados e não outros, ou seja, traz, para o texto, enunciados que têm acolhida no discurso da FD em que está inscrito o sujeito. É nessa perspectiva que as diferentes relações sociais, em que se insere o sujeito, demonstram, por conseguinte, o caráter político.

Não há sujeito, nem sentido que não seja dividido, não há forma de estar no discurso sem constituir-se em uma posição-sujeito e, portanto, inscrever-se em uma ou outra formação discursiva que, por sua vez, é a projeção da ideologia no dizer. As relações de poder são simbolizadas e isso é o político. (ORLANDI, 2012b, p. 55) 
EID\&A - Revista Eletrônica de Estudos Integrados em Discurso e Argumentação, Ilhéus, n. 14, jul/dez.2017.

No caso da presente apreciação, tratamos de uma tomada de posição social que é também de ordem política. Nela são evocadas certas regularidades, produzidas pelas relações de força/ mercado que produzem sentidos sobre regras semelhantes dentro de um contexto que, por um lado, percebe a carne apenas como alimento e, por outro, como bem de consumo. Nesse ponto, focaremos na materialidade discursiva (texto verbal e não verbal) que alicerça nossa análise, respeitando os domínios da FD no contexto analisado. A condição de existência desta análise são as margens do discurso, em que se produzem direcionamentos a partir dos quais se estabelecem pontos de convergência para diferentes direções que proporcionam pistas acerca dos efeitos de sentido produzidos pela publicidade da empresa FRIBOI.

Reproduzir consensos sociais a partir do interdiscurso é trazer à tona os aspectos da FD quanto às relações de conhecimento de mundo, conhecimento linguístico e conhecimento do sujeito. Ao nos expormos aos enunciados, ora analisados, constatamos que a presença da heterogeneidade da FD pode corresponder também à heterogeneidade da posição-sujeito que revela aspectos que fazem o discurso estabelecer as contradições inerentes às diferentes posições-sujeito que a mesma abriga.

Os enunciados em análise propõem um diálogo entre as diferenças e semelhanças no interior da FD, constituindo pontos de encontro e divergência para análise, a fim de caracterizar a FD como um espaço de oferta e procura. Sendo assim, passemos ao discurso da publicidade em questão sobre a égide da AD.

\subsection{Objeto de análise}

O caráter simbólico referente ao consumo de carne não está apenas em nossa memória histórica, está presente em nossas relações diárias e são utilizadas por instituições alimentícias. A empresa Friboi, marca da JBS, traz em seu site1 a história de criação, em 1953, com José Batista Sobrinho, "filho de um operário que havia se mudado para Brasília" e "com boa visão de futuro, seu Zé Mineiro enxergou nessa mudança a oportunidade de alimentar todas pessoas que também estavam indo para a capital do país". Observamos que a marca busca criar um efeito de união da ideia visionária de um sujeito com a sua origem (filho de operário) para possivelmente aproximar-se da população.

\footnotetext{
${ }^{1}$ História da Friboi. Disponível em: <https://www.friboi.com.br/a-empresałhistoria>. Acesso em 10 jan. 2017.
} 
EID\&A - Revista Eletrônica de Estudos Integrados em Discurso e Argumentação, Ilhéus, n. 14, jul/dez.2017.

Ressaltamos que a missão ${ }^{2}$ da empresa envolve as seguintes expressões: "simplicidade e honestidade, sempre"; "amor pela nossa terra"; "caprichamos nos produtos"; "sustentabilidade? trabalhamos"; e, "fazemos por onde para ter sua confiança". Palavras que são rememoradas em suas campanhas publicitárias em forma de vídeo e/ou imagens. Um fato que nos chama atenção é o slogan da campanha publicitária: "Friboi. Carne confiável tem nome".

Neste slogan, entendemos que o produto oferecido pela empresa Friboi não é apenas uma referência à carne enquanto alimento, mas atribui ao produto qualidades como confiança e excelência, que vão além das adjetivações comuns ao produto, como: maciez, suculência, sabor, entre outros. Para tanto, a empresa se vale de algumas estratégias presentes na linguagem publicitária como o argumento de confiança e de linguagem imagética, que apresenta ao consumidor as perspectivas do novo produto dentro de uma rede de significados.

O slogan, associado à empresa, faz sua consolidação através da utilização enfática da expressão: "É Friboi", que acaba por se tornar uma metáfora utilizada em vários meios sociais a fim de caracterizar a qualidade de algo. $O$ uso da expressão nos remete às relações linguísticas as quais se perpetuam na esfera publicitária e, internalizadas pelo sujeito, são proferidas, ironicamente ou não, para indicar algo com qualidade.

Ao tratarmos da carne, alimento comercializado pela empresa Friboi, trazemos o que ela abarca, ou seja, ela abrange as relações sociais e suas referências históricas e afetivas. Com isso, temos na produção publicitária da empresa, que pode ou não se consolidar na esfera social, um universo de possibilidades de análise.

Das mais diversas formas de preparo até a mesa, a empresa Friboi parece nos expor o alimento com possibilidade de consumo confiável de carne. Dotado de grande simbologia, este alimento é povoado de significados que reportam à história que nos constitui como brasileiros. Para uma melhor compreensão do objeto de nosso trabalho, apresentamos, na Figura 1, a publicidade ${ }^{3}$, divulgada pela comunidade/ fanpage no Facebook da Friboi.

\footnotetext{
${ }^{2}$ Missão da Friboi. Disponível em: <https://www.friboi.com.br/a-empresa\#missao>. Acesso em 10 jan. 2017.

3 Publicidade da Friboi. Disponível em: <https://www.facebook.com/Friboi/photos/a.235772766501146.54870.190596814352075/503931679 685252/>. Acesso em: 10 abr. 2017.
} 
EID\&A - Revista Eletrônica de Estudos Integrados em Discurso e Argumentação, llhéus, n. 14, jul/dez.2017.

\section{Figura 1 - Publicidade da Friboi}

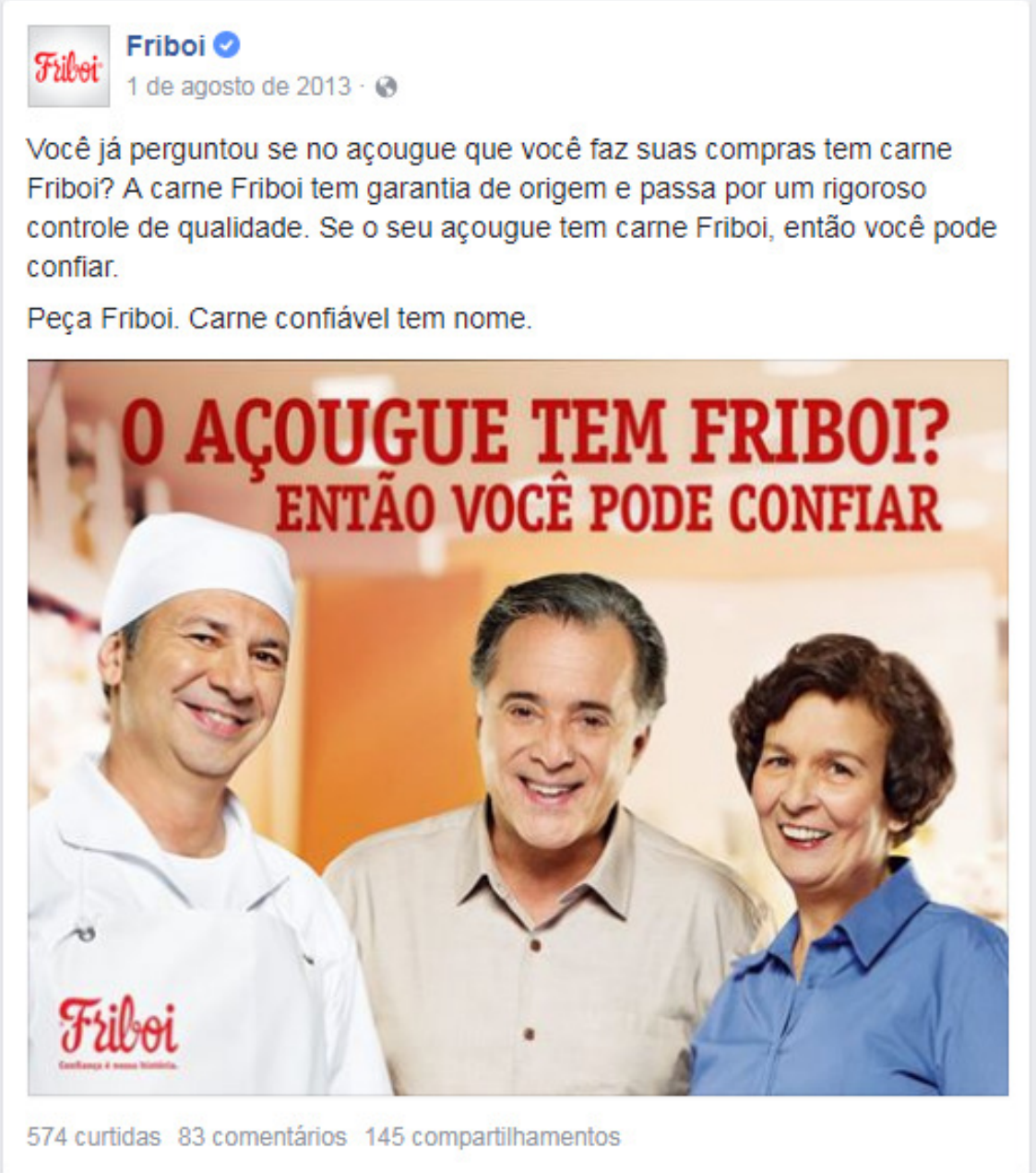

Fonte: https://www.facebook.com/Friboi

Observamos que a postagem (Figura 1), realizada pela empresa Friboi, obteve 574 curtidas, 83 comentários e 145 compartilhamentos, números positivos para uma das tantas imagens que circulam nessa fanpage. A comunidade tem mais de um milhão de inscritos, o que pode facilitar a circulação da mensagem e os compartilhamentos. Não nos deteremos à análise do chamamento da postagem, mas destacamos a repetição da palavra "carne" acompanhada, por três vezes, da marca "Friboi" e, seguida da adjetivação "confiável”. Outro detalhe, pouco evidente visualmente, é que o jaleco do possível açougueiro tem, no lado direito, em impressão vermelha, cor da marca, o dizer "Friboi Confiança é nossa história". Todos esses pormenores conectam-se à marca Friboi, seja pela palavra confiança associada à carne ou à história da empresa. 
EID\&A - Revista Eletrônica de Estudos Integrados em Discurso e Argumentação, Ilhéus, n. 14, jul/dez.2017.

Para essa análise, partiremos dos enunciados “O açougue tem Friboi?”, doravante referido como E1, associado a sua resposta "Então você pode confiar", que será referido como E2, presentes no topo da campanha publicitária. Esta associação de pergunta e resposta, contextualizada aos elementos visuais que os circundam faz emergir um universo de questionamentos como: Para quem? Em que contexto vale a interrogação "O açougue tem Friboi?”. E a resposta “Então você pode confiar"? A partir de que lugar afirma-se isso? Que fronteiras margeiam o ponto de interrogação? Haveria outras possibilidades de sentido? Que outros enunciados se inscrevem, com ou sem polêmica nessa rede de dizeres?

Com intuito de constituir as respostas para essas tantas questões é que iniciamos nossa reflexão teórico-analítica. Buscamos trabalhar com os discursos (quase) invisíveis do cotidiano, fundamentados nas noções de formação discursiva e efeitos de sentido, revelados pelas condições de produção do discurso.

\subsection{A materialidade discursiva}

Enquanto tessitura, a materialidade discursiva nos remete ao entrelaçamento de linhas coerentes que proporcionam a compreensão daquilo que se expõe. Seguindo essa perspectiva, entendemos que a publicidade em questão se vale de aspectos que constituem o discurso a partir de texto verbal e não verbal.

O texto não verbal é uma materialidade típica da publicidade, mas não se faz presente apenas pelo seu caráter ilustrativo, e, sim, devido às possíveis interpretações que são evocadas pelo leitor. Ao observarmos, em primeiro plano, a imagem de três pessoas, tentamos ligá-las ao nosso gesto interpretativo e atribuir sentidos, entendendo que a mesma, presente na publicidade, demonstra certo contentamento.

O sorriso é comum a cada um das personagens da publicidade, mas diferenciamos cada uma pela sua vestimenta. A vestimenta é algo significativo para nossas amarras de sentido, visto que um dos homens, o da esquerda, está vestido de branco e com avental e uma touca, o que remete ao aspecto de limpeza trazido pela cor. O homem posicionado ao meio, por sua vez, está vestindo uma camisa social acinzentada, o que corrobora para o efeito de seriedade e de sobriedade trazida pela vestimenta e quem a veste, no entanto, nada garante que esse sentido se concretize, pois quem determina o sentido é a 
FD em que os sujeitos imaginariamente se inscrevem. Com isso, é interessante determos a atenção à única personagem feminina que aparece na publicidade, usando uma camisa e, aparentemente, vinculando-se ao efeito de sentido dado à vestimenta do homem, apenas diferenciando-se pela cor azul. Ainda sobre a materialidade imagética, o texto não verbal, é importante remetermo-nos ao suposto lugar social de cada personagem na publicidade apresentada.

Nesse ponto, entendemos, imaginariamente, que o homem, da esquerda e de branco, seja um açougueiro, trabalhador do local, e o homem ao meio, o ator renomado na dramaturgia brasileira Tony Ramos e a imagem que ele representa junto ao público, como um sujeito com o diferencial de ter protagonizado muitos personagens de bom caráter, o que reforça os sentidos de confiabilidade que deslizam para o produto em questão.

Por fim, compreendemos que a personagem feminina não apresenta um lugar social definido, uma vez que não há indícios nem de sua profissão, mas de que seja talvez uma possível consumidora do produto da empresa Friboi. A presença de uma mulher, uma senhora de meia idade e distinta, branca, bem vestida e que estaria satisfeita com o produto é veiculado na publicidade, o que possivelmente pode aproximar outras senhoras que compartilhem das mesmas características.

$\mathrm{Na}$ perspectiva do texto verbal, podemos nos remeter a algumas relações primordiais ao discurso argumentativo publicitário que se consolida pelo uso de um enunciado atrativo e imperativo de identificação da marca "FRIBOI". O uso dessa linguagem procura atrair a atenção do sujeito interlocutor, deixando aparecer o caráter publicitário que é atingir seu público alvo, a fim de que haja a consolidação do ato da compra.

Os enunciados observados são representativos do discurso da FD mercantilista, representativa da empresa Friboi. Em um primeiro momento, notamos o uso de uma oração interrogativa (E1) que se associa simultaneamente a uma resposta (E2). $O$ fato da pergunta (E1) "O açougue tem Friboi?" trazer a marca do produto e ter como resposta (E2) "Então você pode confiar", nos direciona a aspectos que condensam a importância da FD que, por sua vez, dissimula as relações sociais da publicidade em pauta. Podemos pensar que estes enunciados podem produzir uma infinidade de sentidos que não estão apenas na esfera do dito/escrito, pois aí jogam relações de força presentes na sociedade. 
EID\&A - Revista Eletrônica de Estudos Integrados em Discurso e Argumentação, Ilhéus, n. 14, jul/dez.2017.

Em E1, por exemplo, Friboi tem o nome associado aos produtos comercializados em um açougue, dando à marca um caráter de substantivo próprio que o diferencia dos demais produtos, oferecidos neste tipo de estabelecimento comercial. Também na resposta, presente em E2, observamos o uso do pronome "você" que assinala a aproximação com o público alvo, consumidor da carne, ao produto Friboi que possui um diferencial.

O que entendemos como um suposto diferencial para este produto é o fato da confiabilidade, exposta em E2 e que nos remete a E1, ou seja, faz um caminho circular em que o produto Friboi é algo confiável. Nesse ponto, é que a falta de pontuação em E2 pode caracterizar uma continuidade de sentidos a serem produzidos pelo leitor pela não finalização da sentença.

Outro aspecto a ser analisado é o fato do nome da marca ser associado a predicados durante a sua exposição na mídia, trazendo a ideia de adjetivação como maciez e suculência. O fato dessa informação não estar presente na publicidade analisada não descarta o fato desta relação atribuir sentido aos enunciados em pauta, uma vez que o produto acaba trazendo consigo um deslize resultante de uma metáfora atribuída à marca que acabou se popularizando pelo não dito, que se faz presente em todo enunciado.

A empresa Friboi se vale da publicidade para evocar sentidos que motivam o consumidor a estabelecer vínculos com o produto. Para Orlandi (2012a, p. 76), "há na base de todo discurso um projeto totalizante do sujeito, projeto que o converte em autor", sendo o autor "considerado como princípio de agrupamento do discurso, como unidade e origem de suas significações, como fulcro de sua coerência" (p. 75). O sujeito acredita ser fonte e origem de seu dizer, no entanto, ele é determinado pela exterioridade, o que "é mais um efeito discursivo regido pelo imaginário, o que lhe dá uma direção ideológica, uma ancoragem política" para manter uma unidade representativa dele (idem, p. 77).

Com isso, tentaremos demonstrar as relações presentes nos enunciados E1 e E2 para tentar evidenciar os entrelaçamentos trazidos pela publicidade. Para tanto, valemo-nos dos princípios de comparação oriundos dos enunciados. Essas comparações são as divergências que resultam da recuperação dos sentidos recobertos pelo E1 - "O açougue tem Friboi?", contraposto pelos sentidos de E2 - "Então você pode confiar", cujas relações podem ser tecidas através das interações sintático-semânticas subjacentes a ambos. Trata-se de relações de coesão pressupostas, cujo preenchimento 
EID\&A - Revista Eletrônica de Estudos Integrados em Discurso e Argumentação, Ilhéus, n. 14, jul/dez.2017.

sintático do espaço que se encontra apagado resulta em teias de sentido construídas a partir das posições-sujeito representadas pelos leitores.

Com isso, dependendo das diferentes posições representadas pelos sujeitos que leem, ora pode haver união, ora separação entre ambos. A seguir, E1 e E2 passam a ser analisados como um único enunciado, suprimindo o "então", considerados a partir de relações de aliança ou de divergência, e cujos agrupamentos são posteriormente descritos:

E3 - Carne é Friboi, mas você pode confiar.

E4 - Carne é Friboi logo você pode confiar.

Sobre E3: Conforme este enunciado, compreendemos o uso de um conectivo que atribui uma relação de oposição, entretanto não se encontra uma divergência com o produto e, sim com o público alvo. A instauração dessa discordância no enunciado reporta a um conjunto de sentidos levado à esfera da atribuição de valores tanto do produto quanto da publicidade que resulta no consumo. Já o enunciado "Você pode confiar" não se encontra em divergência direta com produtores, comerciantes e consumidores, alvos do E1, mas afronta a posição representada por aqueles que relacionam o entorno econômicoalimentício. Em E3, mencionamos o fato de que há carnes que podem ser mais confiáveis e, para tanto é atribuído valor, tanto relativo ao caráter de consumo como ao aspecto de diferenciação social, revelando a existência de excluídos do ciclo econômico-social pelo valor monetário atribuído ao produto Friboi. Desse modo, E1 e E2, reconstituídos em E3, trazem as relações sintáticas de adversidade que se inscrevem, de uma parte, em posições-sujeito conflitantes no interior da mesma FD, ao ponto da quase-ruptura.

Sobre E4: Ao agruparmos os enunciados com o conectivo logo, podemos demonstrar o domínio referente à conclusão, o que faz aliança com o consumidor através do ato de comprar, dando ao enunciado o caráter voltado à filiação plena da posição-sujeito/ consumidor à FD da empresa. As questões econômicas emergentes pela via dessa enunciação não são vistos como pontos de caráter social, nem as implicações do consumo de carne como as questões ambientais, de distribuição da terra e de política de produção de alimentos. Em E4, estas implicações podem ser vistas através da associação entre o estabelecimento "açougue", que proporciona a transação da mercadoria, e o consumidor, que pode estar filiado a aspectos ideológicos referentes à origem do produto, podendo relativizar as relações sociais citadas. Essa perspectiva, emergente na reconstituição de E4, coloca-nos 
EID\&A - Revista Eletrônica de Estudos Integrados em Discurso e Argumentação, Ilhéus, n. 14, jul/dez.2017.

diante da posição-sujeito/ consumidor filiado à FD e ao produto Friboi, estando o sujeito atravessado e evitando analisar os demais produtos que 0 satisfaçam, confiando na empresa.

Assim, E1 e E2, enquanto partes, compõem um todo, que não é, no entanto, possível de fragmentação, pois cada um deles pode convergir ora para uma mesma posição-sujeito no interior da FD, ora para posições-sujeito diversas. Os enunciados reencontram-se no produto de uma construção/desconstrução dentro do âmbito parafrástico, o que é demonstrado pela ruptura da ordem da estrutura. O E1, "O açougue tem Friboi?", é paráfrase de "O açougue tem carne de qualidade?”, repetição que já é produto de uma variação de sentidos, pois, ao fazer a associação do produto comercializado e do consumo de carnes, presenciamos a convergência para um contexto que pode ser entendido como de diferenciação, dados os aspectos já discutidos, uma vez que a qualidade está atrelada ao produto que agrega valores.

Já o enunciado E2, também privilegia o aspecto de ruptura, pois o enunciado "Então você pode confiar" remete-nos à possibilidade da carne ter o seu diferencial referente à confiabilidade e retoma o aspecto semântico do uso do verbo confiar, que não possui complemento no enunciado e remetemse mais uma vez a E1 e sua paráfrase já mencionada. Este aspecto de retomada recai na consolidação de uma ruptura dentro do contexto dos enunciados.

As estruturas parafrásticas e de comparações fazem com que compreendamos as relações de sentido presentes na publicidade da empresa Friboi. Isto nos leva a deduzir que há efeitos de sentido na publicidade que estabelecem uma relação de confiança entre o produto e o consumidor. Também, há pontos em que os não-ditos reiteram as relações de diferenciação social, já que o produto é consumido apenas por uma parcela de consumidores de carne que possuem condições econômicas para adquiri-la.

Com esta análise, não podemos deixar de entender o quanto a publicidade provoca um entrecruzamento de enunciados no interior da FD, resultado de sentidos recobertos nos textos que compõem a materialidade discursiva. Cabe salientar que os aspectos textuais/enunciativos são agrupados, nesta análise, com a ideia de observar a inserção do sujeito na cultura e sua posição no contexto sócio-histórico, o que permite uma reflexão apontada pelos princípios da AD. 
EID\&A - Revista Eletrônica de Estudos Integrados em Discurso e Argumentação, Ilhéus, n. 14, jul/dez.2017.

\section{Considerações finais}

A motivação para a análise surgiu do grande destaque dado pela mídia televisiva à campanha publicitária da Friboi a qual possibilitou um entrecruzamento entre o sujeito e as metáforas associadas aos dizeres da empresa e do garoto propaganda. A partir da análise, entendemos que a materialidade discursiva corroborou para a filiação ou não do sujeito à determinada FD e a produção de novos sentidos que se ligam às relações sócio-históricas.

Os enunciados ora analisados, à luz da $A D$, não se fixam apenas na percepção teórica, a fim de comprovar a eficácia de suas noções, pois queremos, com este trabalho, demonstrar que o discurso publicitário repercute na esfera social. Na configuração da FD representativa da empresa Friboi, indagamo-nos acerca do caráter de convergência e divergência para, assim, entendê-la como uma FD mercantilista, que possui como função principal o ato da compra e venda.

Reiteramos a perspectiva de distinção social dada pela questão mercantilista, em que alguns sujeitos podem não fazer parte da esfera discursiva dos consumidores do produto. Este fato de não pertencimento ou de pertencimento à esfera discursiva consumista é relativizado através das comparações, deixando a entender que alguns aspectos podem aproximar ou distanciar uma posição-sujeito de outra.

O funcionamento discursivo dos enunciados aponta para as relações de ditos e não-ditos dentro de limites tensos da FD, pois, ao nos expormos aos discursos comerciais, tentamos resistir à discursividade publicitária, possibilitada pela opção de não fazer parte dela. Assim, buscamos encontrar maneiras de observar a materialidade discursiva, baseando-nos em uma FD nomeada como mercantilista que abriga os discursos políticos de segregação pelo critério de poder de consumo que aqui fora evidenciado pelo discurso publicitário da empresa Friboi.

\section{Referências}

DAMATTA, Roberto. O que é Brasil? Rio de Janeiro: Rocco, 2004.

CAZARIN, Ercília Ana. A leitura: uma prática discursiva. Linguagem em (Dis)curso LemD. Tubarão, v. 6, n. 2, p. 299-313, 2006. 
EID\&A - Revista Eletrônica de Estudos Integrados em Discurso e Argumentação, Ilhéus, n. 14, jul/dez.2017.

COURTINE, Jean-Jacques. Análise do Discurso Político: o discurso comunista endereçado aos cristãos. São Paulo: EdUFSCar, 2009.

ERNST-PEREIRA, Aracy; QUEVEDO, Marchiori Quadrado de. Uma mesma diferente imagem: que objeto é esse? Entretextos. Londrina, v. 13, n. 2, p. 266-287, 2013.

ORLANDI, Eni P. Análise de Discurso: princípios e procedimentos. 10. ed. Campinas: Pontes Editores, 2012a [1999].

. Discurso em análise: Sujeito, sentido e ideologia. 2. ed. Campinas: Pontes Editores, 2012b [2012].

. A cidade dos sentidos. Campinas: Pontes Editora, 2004.

PÊCHEUX, Michel. Semântica e discurso: uma crítica à afirmação do óbvio. Trad. Eni P. Orlandi et al. 4. ed. Campinas: Ed. da UNICAMP, 2009 [1988].

. O discurso: estrutura ou acontecimento. Trad. Eni P. Orlandi. 4. ed. Campinas: Pontes Editores, 2008 [1998].

Publicidade da Friboi. Disponível em: <https://www.facebook.com/Friboi/photos/a.235772766501146.54870.1905968143520 75/503931679685252/>. Acesso em 22/07/2017.

RECUERO, Raquel. O capital social em rede: como as redes sociais na internet estão gerando novas formas de capital social. Contemporânea: comunicação e cultura. Salvador, v. 10, n. 03, p. 597-617, 2012.

THUROW, Ane Cristina; DOROW, Clóris Maria Freire. Discurso na fanpage "Só Gordinhas" sobre a personagem Perséfone da novela Amor à Vida. Cadernos de Estudos Linguísticos. Campinas, v. 57, n. 2, p. 228-247, 2015.

Forma de citação sugerida:

THUROW, Ane Cristina; CAZARIN, Ercília Ana; SCHNEIDER, Jeferson da Silva. Carne é Friboi? Análise discursiva de uma campanha publicitária no Facebook. EID\&A - Revista Eletrônica de Estudos Integrados em Discurso e Argumentação, Ilhéus, n. 14, p. 35-51, jul/dez.2017.

Recebido em: 20/09/2017

Aprovado em: 27/11/2017 